\title{
Space Career \& Educational Opportunities through the ASTRI Programme
}

\author{
K.Papavramidis, B. Ordoubadian, A. Welch, S. \\ Wizemann, A. Barot-Froger, F. Margiotta \\ OHB System AG, Manfred-Fuchs-Straße 1, \\ 82234 Weßling, Germany \\ konstantinos.papavramidis@ohb.de
}

\begin{abstract}
The following paper describes the purpose and benefits of the Advanced Student Team Research in space Industry (ASTRI) programme, as well as an example and programmatic outcome of a pilot project under the programme implemented by OHB SE.
\end{abstract}

The ASTRI programme is a collaboration between European universities and private aerospace companies, and seeks to provide a structured transition between students' academic curriculum and their entry into the industry. There are three main ASTRI stakeholders, and their positive outcomes of participating in the programme are identified and listed. One of the main benefits is the establishment of a young and well-prepared talent pool of engineers.

OHB System, an established industry actor based in Germany, and the OHB SE subsidiary Blue Horizon, based in Luxembourg, participated in the first round of the ASTRI programme by proposing a project to develop a viable commercial micro moon lander concept.

For their ASTRI project, OHB implemented new approaches such as Concept Maturity Levels (CMLs) as a way to structure an 18-month long phase 0/A/B1 feasibility study. Each team member was given a role in the project. The roles typically included a technical aspect, where each member was responsible for designing a particular subsystem of the spacecraft, and a nontechnical aspect, which could include topics such as business development, cost analysis, and project control.

The technical output of OHB's project include a developed lander concept seeking to accommodate a wide variety of customers and payload types by providing not only transportation to the lunar surface, but also necessary infrastructure needed by the payloads to successfully complete their missions. These infrastructure service concepts are geared towards eventually providing support for permanent human lunar settlement, a vision that will hopefully bring space exploration closer to the public and inspire the next generations.

Finally, the lessons learned by the team of students participating in OHB's ASTRI pilot project are presented. These lessons outline suggested improvements for future implementations of projects under the ASTRI programme, both at $\mathrm{OHB}$ and at other companies, in the hope that the opportunities that ASTRI introduces for students, universities, and companies are further enhanced.

\author{
K. Hoult-Ellingworth, C. Grace, N. Faber \\ Blue Horizon Sàrl, 11 rue Pierre Werner, \\ L6832, Betzdorf, Luxembourg \\ kyle.hoult-ellingworth@bluehorizon.space
}

Keywords-ASTRI; Moon; Lunar Lander; OHB System; Blue Horizon; KTH Royal Institute of Technology; University of Leicester; ISAE-Supaero; University of Stuttgart;

\section{INTRODUCTION OF THE ASTRI PROGRAMME}

The European space sector is expanding quickly, exposing an existing lack of skilled space engineers available to fill advertised vacancies. At the same time, the typical difficulties of entering the workforce with only an academic degree and little work experience remains a barrier to these same vacancies for those soon-to-be or recently graduated. The Advanced Student Team Research in space Industry (ASTRI) programme is an initiative intended to fill this shortage of engineers in Europe by closing the gap between students' academic and working career.

Spearheaded by Jean-Jacques Dordain, the former Director General of ESA, ASTRI is in essence a combination of a typical master's thesis project and an ESA Young Graduate Trainee (YGT) programme. Instead of being held at ESA however, ASTRI connects master's students from European universities with established private European aerospace industry actors. These private companies are invited to propose suitable projects they are interested in pursuing internally, after which students from the participating universities apply to said projects. The application process resembles a typical job vacancy application, and includes technical interviews. Students who are selected are grouped up to work together in a highly diverse team environment, intended to expose them to the typical international working culture of European aerospace companies [1].

The students are assigned individual work packages for the 18-month project, from which suitable thesis topics can be chosen. Fig. 1 shows the intended breakdown of an ASTRI project timeline. For the first six months, the participants work as typical students writing their master's thesis while located at their respective universities while being paid by the industrial partner. During the remaining twelve months, the team members relocate to continue the project at the companies as regular employees. This natural transition makes ASTRI a unique 


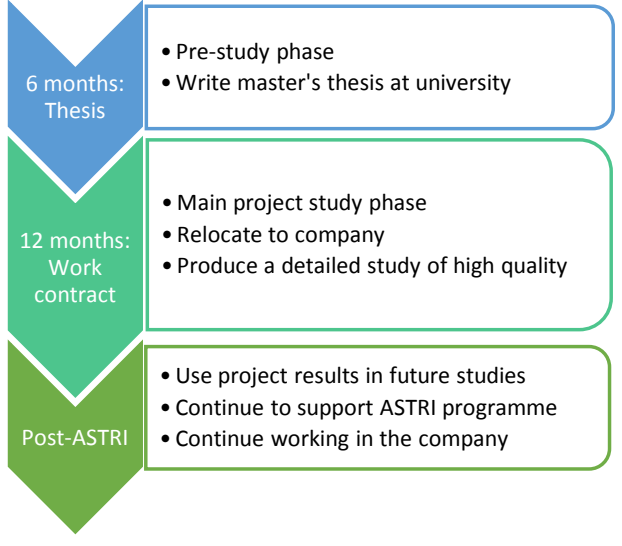

Fig. 1. Proposed ASTRI project timeline.

programme that facilitates the writing of high-quality theses with the help of a private company. The output of these theses are then immediately used to support a broader project with practical implications. This approach enables the students to both finish their master's degree while getting similar working experience that a YGT programme provides to entry-level engineers.

The goal of this paper is to raise interest in stakeholders, including students, universities, and companies, to participate in and take advantage of the great opportunities and benefits provided by the ASTRI programme.

\section{ASTRI STAKEHOLDER PARTICIPATION BENEFITS}

There are several benefits for each of the three individual participating stakeholders in the ASTRI programme, and these have been identified and are described below.

\section{A. Benefits for Students}

- Gathering of practical project experience in a real industrial environment and learning how the space industry works first-hand. This helps ease the career transition between academia and industry.

- Learning from industrial and institutional experts to apply the best approaches from both fields. Advice and guidance gathered while working on the project can help improve the skillset of the students.

- Working on innovative and highly interesting projects, which have an impact on the current environment of the space industry. This gives the students a relevant, modern look at the space industry to grant useful experience for future projects of a similar nature.

- Networking with industrial and academic experts as well as colleagues in an international environment. Knowing various work partners and organisations internationally leads to useful business connections for guiding and aiding career paths.

- Improving social skills by working in a highly multicultural environment. Working alongside colleagues from different nations and ethnicities allows for expanding perspectives and skillsets.

\section{B. Benefits for Universities}

- Expanding on student-led research developed in cooperation with private companies. Universities gets a chance to access and influence cutting-edge research influenced through their ASTRI students.

- Establishing stronger professional connections between the academic world and private industry to facilitate potential partnerships and relationships. The networking ASTRI enables can be used as a gateway for future research projects to be conducted, partially funded, and completed in cooperation with these companies.

- Improving university course content by creating a feedback dialogue between industry leaders and academics, allowing universities to tailor courses to industry standards. This improves employment prospects of graduates, which can further enhance the appeal of the university.

- Increasing recent graduate employment numbers, demonstrating high employment prospects for universities participating in the ASTRI programme. ASTRI has the potential to improve the career prospects of the alumni.

\section{Benefits for Companies}

- Obtaining technical outputs created as part of its ASTRI project implementation. Successful, viable elements of the resulting deliverables can be used directly for commercial gain or can be partially incorporated into other projects.

- Providing access to potential employees who have already been vetted to help fill internal vacancies. Furthermore, companies have the opportunity to guide, train, and develop young engineers into specific roles required by the company.

- $\quad$ Creating PR and company outreach to universities. The ASTRI programme has allowed university students to become more aware of these companies and this can help students, as potential future employees, learn about possible future employers.

- Creating parallel working opportunities on both the ASTRI project and other concurrent projects in need of staff. This helps the company immediately relieve its need for additional workers while giving further training to the ASTRI students.

- Testing team-working strategies across other remote sites and the use of concurrent engineering. The separation between team members allows for a unique environment for testing new tools, project management structures, communication tools and methods, and trial implementations of new workplace strategies. 


\section{ASTRI-OHB PROJECT IMPLEMENTATION}

With the benefits of the ASTRI programme described, an example is given of how OHB System and Blue Horizon chose to implement its ASTRI pilot project.

\section{A. Commercial Micro Moon Lander Theme}

The theme of the project proposed by $\mathrm{OHB}$ is due to the recent attention that has been directed back to the Moon. Half a century ago, lunar exploration was politically driven by large government budgets, a necessity due to the enormous cost of resources involved. Due to the current NewSpace trend to faster develop better and cheaper access to space, the cost of participating in space exploration in general has been drastically reduced, enabling commercial endeavours and private actors to participate as well. Today, the private sector is being encouraged to participate in the renewed push for lunar exploration, thus allowing the free market to develop goods and services needed for a sustainable future lunar colony at a higher quality and lower cost than the public sector ever could. Both NASA and ESA, as well as some private organizations, have started projects and initiatives to encourage companies to help humanity return to the Moon, this time to stay for good. It is in this positive lunar exploration environment that OHB wants to get involved, and part of their approach is to assign the ASTRI-OHB team to study how $\mathrm{OHB}$ can join the commercial lunar exploration market.

The scope of the project proposed by OHB System and Blue Horizon is to develop a commercial micro moon lander service concept. This lander study would form the basis of a cargo delivery service intended to deliver customer payloads safely to the lunar surface. The commercial aspect of the concept was included in an attempt to expand OHB's potential revenue streams. The "micro" aspect limited the absolute size of the spacecraft, and one of the main difficulties of the study was to establish a financially viable, and sustainable, commercial service while maintaining this sizing constraint.

The current emerging commercial lunar exploration market is led by companies such as Astrobotic (USA), Israel Aerospace Industries (IAI) (Israel), and PTScientists (Germany). These potential competitors are all veterans of the Google Lunar XPRIZE competition and have close to a ten-year head start. The ASTRI-OHB team must find and develop its own niche to remain attractive to customers and remain viable to the company, in this competitive lunar lander environment.

Sustainability of the developed commercial service is crucial, as the target is not just the lunar surface. The Moon is viewed as a suitable staging ground and practice arena for eventual manned Mars missions and beyond. Supporting the necessary long-term human outposts, such as NASA's Lunar Orbital Gateway-Platform and the ESA's Moon Village, is a long-term goal of the CMML. As part of ensuring sustainability, OHB has also signed collaboration agreements on lunar landing missions with both IAI and Blue Origin (USA), and the ASTRIOHB concept study needs to be folded into this collaborative environment to have the greatest impact.
The following mission statement has been constructed to communicate the main idea of the commercial service concept: "Due to the increasing interest in lunar applications, there is a growing need for a reliable transportation system that provides commercial access to the Moon. The ASTRI-OHB team will establish a regular and affordable payload delivery service to the lunar surface. The service is aimed at customers looking to perform rapid and iterative technology demonstrations, scientific experiments, and prospecting missions while promoting the development of a permanent lunar settlement". This mission statement tries to capture the team's core vision that has been held and refined throughout the project's lifetime.

\section{B. ASTRI-OHB Project Structure \& Roles}

The study began with a kick-off meeting at the company location, where the students travelled to attend. This first meeting helped students to get to know each other and the team they will be working with [2].

The ASTRI-OHB team consists of nine members: eight students and one project manager. The student team is composed of six different European nationalities coming from four different European universities. Each student is allocated to an area of technical expertise with a Working Package (WP), as denoted by the various spacecraft Sub-Systems ('S/S'), as can be seen in Fig. 2. The students then selected an individual thesis topic in coordination with their thesis advisor and the project manager based on their S/S and their field of expertise that they would be working on. Each WP includes several technical and programmatic activities such as Mission Analysis, System and $\mathrm{S} / \mathrm{S}$ design.

In addition to the distributed technical WPs, various nontechnical roles were also split among the team. As the project is commercially oriented, a business developer and a cost analyst are required. One member is responsible for outreach and is in charge of every link between the team and external affairs. Finally, a project controller is in charge of establishing a project timeline to keep tracks of issues and tasks throughout the project. Those various non-technical roles help the team to develop the necessary skills that are important to be able to support other projects, and the company as a whole.

While the main objective was to learn how to accomplish a high-quality study, there were additional secondary objectives enticing for $\mathrm{OHB}$ as outcomes of the project. The participating students should take the chance to get to know the company from within, and to participate in different projects in parallel to the ASTRI-OHB study. This desire was included to both let the students broaden their learning opportunities and to allow $\mathrm{OHB}$ to temporarily fill vacancies where there was an immediate lack of skilled employees. 

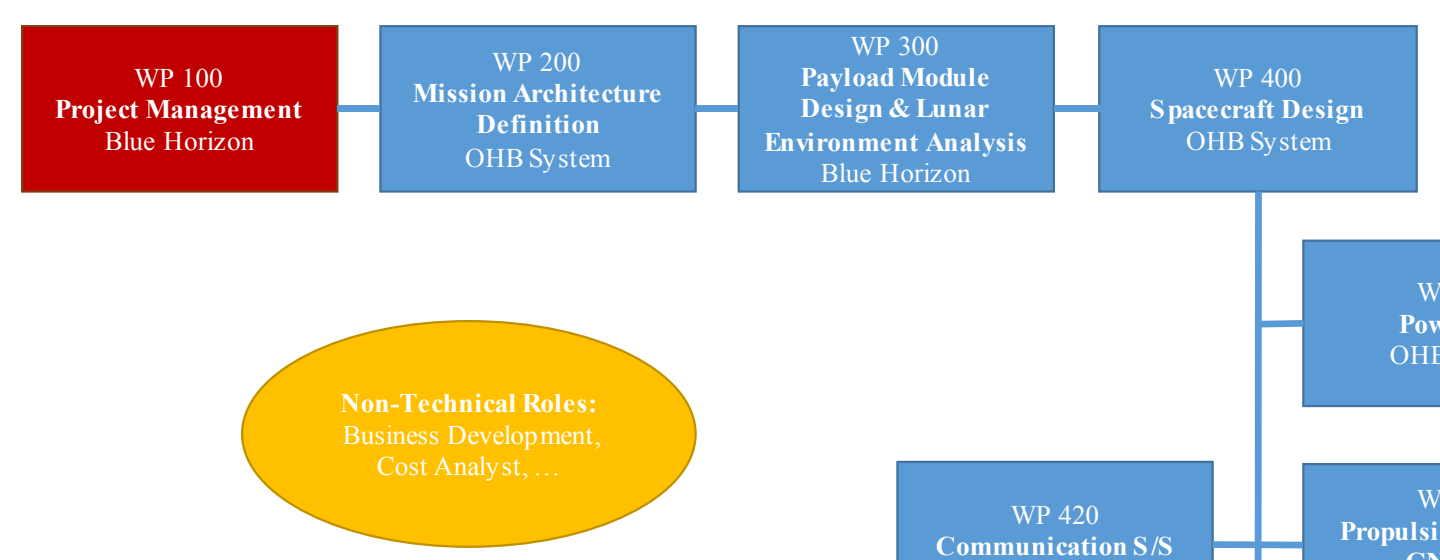

\section{Responsibilities:}

OHB/Blue Horizon Experienced Engineer

Student/Young Graduate - Technical

Student/Young Graduate - Non-Technical

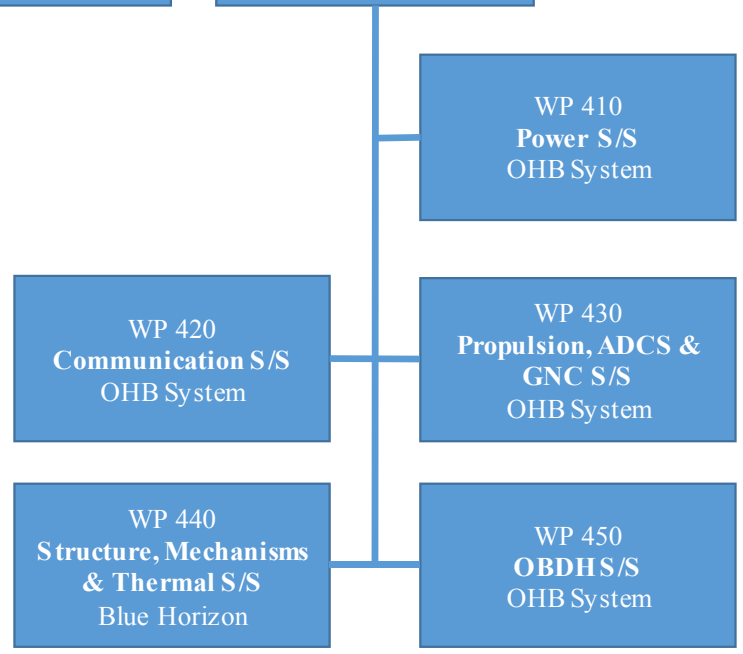

Fig. 2. ASTRI-OHB project structure and WP allocation.

Another objective assigned to the team was to propose the usage of new communication and exchange tools, as well as new ways to implement concurrent engineering. This objective was necessary due to the geographic differences of the team members during the initial 6-month thesis project phase and the high IT Security standards of the company. Several solutions were adopted, such as the Remote Desktop application for remote document and tool access, and the concurrent engineering software IDM-CIC. The implementation of these tools was tested in various remote workshops and team meetings, showing their capability of satisfactorily improving work efficiency. Furthermore, additional solutions were identified as highly interesting for the application in the company but could not be implemented within the frame of the project.

OHB chose to implement a specific project structure, known as Concept Maturity Levels (CMLs), to organize the project. The CML approach contains nine milestones to reach and fulfil, corresponding to phases $0 / \mathrm{A} / \mathrm{B} 1$, and were developed by NASA's Jet Propulsion Laboratory in order to have a solid predevelopment plan up to a project's Critical Design Review (CDR) [3]. Each of the levels have numerous tasks to complete in order to go from one level to the next. At the start of each new level, the team agreed upon which tasks would be tackled for the next milestone review and these tasks were kept track of by the project controller.

\section{ASTRI-OHB LESSONS LEARNED}

With the first batch of ASTRI projects wrapping up, the lessons learned by the ASTRI-OHB team are compiled to help future programme participants have a better ASTRI experience and to improve the efficacy of the programme. Comments about the project have been separated into identifying project elements that went well, those that should be improved upon, and those that went wrong.

\section{A. What Went Well}

- The dedicated time given to learn about all facets of a project, including technical, management, financial, etc. This allows for familiarisation with the project, enabling students to assist in more areas than just their assigned work packages.

- The transition from university to company. By assisting the students with this transition, company processes, private industry logic, and desired company skills can be instilled in the recent graduates.

- The different project opportunities available to the students. As company employees, the students are capable of working on other company projects in parallel to ASTRI, allowing them to gain additional working experience.

\section{B. What Needed Improvement}

- A technical internal advisor should be assigned to each team member already before the kick-off of the project, to provide proper guidance. This issue was identified as a critical point as numerous times the lack of experience by the students lead to complications, delays, mistakes, and avoidable challenges if someone had been available to point out the issue earlier. The company should also spread awareness internally so colleagues are aware, and thus able, to assist the team where expertise is required.

- The project could be built to better accommodate university involvement. Aside from technical assistance during the first 6 months of the project, university involvement was smaller than anticipated. Ideally, 
universities would work with the companies more closely to attend reviews as reviewers. One solution to this is ensuring that Non-Disclosure Agreements (NDAs) are signed before the project begins. Awareness of the programme within the universities was small, and this too could be improved by potentially linking the project to research within the university. This could also be used to help set up projects with universities and the companies, which in turn could further involve the students.

- External reviewers should provide feedback within the first few months to ensure that their comments can be implemented effectively. Input from external reviewers was received late in this project but this feedback would have been good to have earlier on.

- Organize lectures and workshops for team members to help them develop basic skills and knowledge needed for the specific project. The students' academic background may not have provided all technical (or non-technical) skills needed to complete a project at an industry level. Through this process, the company can identify workshops needed for all employees as well.

- To prevent that high IT-Security standards prevent the students from testing new tools, a sandbox environment could be implemented in which the students can test new tools without violating the IT-Security.

- Communicate in advance the tools already used and the tools the different departments are interested in as an input for the selection of tools used by the students to maximize the outcome for the company.

\section{What Went Wrong}

- Some problems arose due to the CML tasks being geared towards scientific missions, and it was determined that the CML structure should be modified to fit commercial mission development. Consequently, the reviews at each level were missing deliverables needed when designing a commercial concept while including unnecessary scientific tasks.

- Access to digital tools like CAD software was highly or completely restricted because of limited number of licenses or because of licensing issues between OHB System and Blue Horizon, because they are located in different countries. The consequence was that for some tasks the mandatory tools were not available.

In order to improve the overall ASTRI programme concept, an "ASTRI Alumni" group should be established and gather at regular annual or bi-annual meetings, both to collect feedback from multiple ASTRI project teams and to network between the teams.

\section{CONCLUSION}

The ASTRI programme is intended to enrich the European aerospace industry with a new approach to introduce newly graduated students into the work force. The programme realizes this by establishing a team of students who work together within their master's theses on the same project in an industrial project frame. The participation of academic and industrial advisors gives the participating team members a chance to learn from both, and provides at the same time unique networking opportunities in an international working environment.

OHB implemented their ASTRI project as a phase 0/A/B1 study on a commercial micro moon lander. The theme of the project highly motivated the team and expanded their scientific, technical, and programmatic experience in a currently hot topic in the space industry. The results and outcomes of the project study will flow into the other lunar activities at $\mathrm{OHB}$, and will help develop the various cooperation agreements already established between OHB and other international companies involved in lunar exploration.

The ASTRI-OHB pilot project revealed certain issues of the first implementation of the programme. Some prior preparation for an ASTRI project is required, such as contacting sufficient external reviewers, signing NDAs with academic advisors in advance, the accommodation of supporting industrial advisors, and setting up the working environment needed to try new digital tools for communication and engineering.

As a pilot project, a lot of useful information on how to implement an ASTRI project was gathered by OHB. These lessons learned can be used by other companies and OHB itself to improve the next iteration of the ASTRI programme.

\section{ACKNOWLEDGMENTS}

Credit is given to OHB System and Blue Horizon for proposing the project, providing the work environment, and assistance throughout the project. Credit is also given to JeanJacques Dordain and the organisers of the ASTRI programme for providing the opportunity to work on the ASTRI-OHB project. Finally, special mention must be made to Nicolas Faber, $\mathrm{COO}$ of Blue Horizon and project manager for the ASTRI-OHB project.

\section{REFERENCES}

[1] ASTRI Programme. Retrieved August 16, 2019, from http://www.astriprogramme.eu/

[2] At OHB SE, students and graduates are preparing for a career in the space industry with the "Trainee Program" ASTRI. Retrieved August 16, 2019, from https://www.ohb.de/en/news/at-ohb-se-students-andgraduates-are-preparing-for-a-career-in-the-space-industry-with-thetrainee-program-astri/

[3] R. R. Wessen, C. Borden, J. Ziemer and J. Kwok, "Space mission concept development using concept maturity levels" Jet Propulsion Laboratory, California Institute of Technology, Pasadena, CA 91109, 2013 